\title{
Fabrication of an Active Electronic Device Using a Hetero-bimetallic Coordination Polymer
}

Article

Published Version

Creative Commons: Attribution 4.0 (CC-BY)

Open Access

Roy, S., Halder, S., Drew, M. G. B., Ray, P. P. and Chattopadhyay, S. (2018) Fabrication of an Active Electronic Device Using a Hetero-bimetallic Coordination Polymer. ACS Omega, 3 (10). pp. 12788-12796. ISSN 2470-1343 doi: https://doi.org/10.1021/acsomega.8b02025 Available at https://centaur.reading.ac.uk/85906/

It is advisable to refer to the publisher's version if you intend to cite from the work. See Guidance on citing.

To link to this article DOI: http://dx.doi.org/10.1021/acsomega.8b02025

Publisher: American Chemical Society

All outputs in CentAUR are protected by Intellectual Property Rights law, including copyright law. Copyright and IPR is retained by the creators or other copyright holders. Terms and conditions for use of this material are defined in the End User Agreement.

www.reading.ac.uk/centaur 
Central Archive at the University of Reading

Reading's research outputs online 


\title{
Fabrication of an Active Electronic Device Using a Hetero-bimetallic Coordination Polymer
}

\author{
Sourav Roy, ${ }^{\dagger}$ Soumi Halder, ${ }^{\ddagger}$ Michael G. B. Drew, ${ }^{\S}$ Partha Pratim Ray, ${ }^{*}$ \\ and Shouvik Chattopadhyay* ${ }^{*}+0$ \\ ${ }^{\dagger}$ Department of Chemistry, Inorganic Section and ${ }^{\ddagger}$ Department of Physics, Jadavpur University, Kolkata 700032, India \\ ${ }^{\S}$ School of Chemistry, The University of Reading, P.O. Box 224, Whiteknights, Reading RG6 6AD, U.K.
}

\section{Supporting Information}

ABSTRACT: A nickel(II)/lead(II) coordination polymer $\left[(\mathrm{NCS}) \mathrm{Pb}\left(\mathrm{H}_{2} \mathrm{O}\right)\right.$ $\mathrm{LNi}(\mathrm{NCS})]_{\mathrm{n}}\left\{\mathrm{H}_{2} \mathrm{~L}=\mathrm{N}, \mathrm{N}^{\prime}\right.$-bis(3-methoxysalicylidene)propane-1,3-diamine $\}$ has been synthesized and characterized. The band gap $(3.18 \mathrm{eV})$ calculated from Tauc's plot suggests the semiconducting nature of the complex. The material has a photosensitivity of 5.76, indicating its applicability in the fabrication of photosensitive devices. The complex has been successfully applied in a technologically challenging thin-film photosensitive Schottky device.

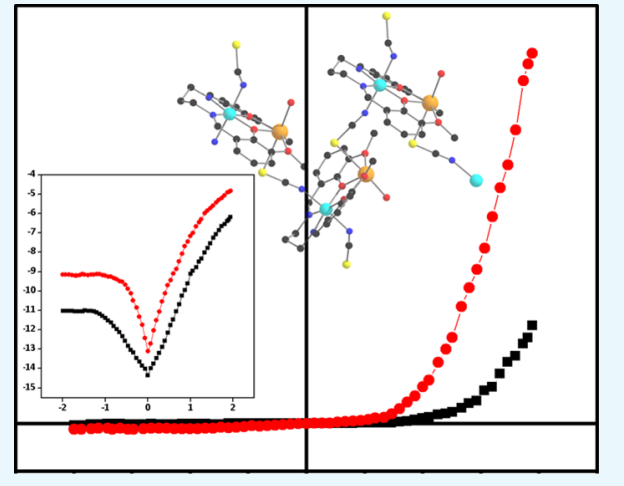

\section{INTRODUCTION}

Coordination polymers (CPs) have attracted the interest of coordination chemists for the last few years for their application in gas absorption, magnetic material, catalysis, luminescence, drug delivery, sensor technology, etc. ${ }^{1,2}$ Although application of some organic materials in lightemitting diodes ${ }^{3}$ and field effect transistors ${ }^{4}$ is known, fabrication of an active electronic device using CPs is not well explored till date. Some $\mathrm{d}^{10}$ metals have the ability to increase the intensity and shift the wavelength of emission of organic ligands by metal coordination, and therefore $\mathrm{d}^{10}$ metalbased CPs were used in optoelectronic devices. ${ }^{5}$ There are reports in the literature regarding the fascinating application of some semiconducting CPs in photovoltaics ${ }^{6}$ and other optoelectronic devices. $\mathrm{N}_{2} \mathrm{O}_{2} \mathrm{O}_{2}{ }^{\prime}$ donor compartmental Schiff base ligands have been widely used for the preparation of hetero-dinuclear complexes. ${ }^{8}$ These could then be linked using suitable pseudohalides $\left[\mathrm{NCS}^{-}, \mathrm{N}_{3}{ }^{-}, \mathrm{NCO}^{-}\right.$, and $\left.\mathrm{N}(\mathrm{CN})_{2}{ }^{-}\right]$to generate various CPs. ${ }^{9}$ Although any member of the first transition series is a good choice to be placed in the inner $\mathrm{N}_{2} \mathrm{O}_{2}$ compartment of such ligands, nickel(II) is preferred for its ability and flexibility to bind both hard and soft donor centers with equal ease and to adopt varieties of geometries with different coordination numbers, oxidation states, and its applicability extending from organometallic to biological chemistry. ${ }^{10}$ On the other hand, the coordination chemistry of lead(II) is also interesting for its potential to form hemi- as well as holo-directed complexes with coordination numbers ranging from 2 to $10 .{ }^{11}$ However, it must be remembered that lead is hazardous to pollution and health ${ }^{12}$ and must be handled with great care. Any semiconducting material showing rectifying nature in a metal-semiconductor (MS) junction can be applied in the Schottky device. ${ }^{13}$ The nonlinear rectifying behavior of $I-V$ characteristics of that material-based device measured under dark and illumination conditions proves its photosensitive Schottky diode character. ${ }^{14}$ However, to the best of our knowledge, there is no report in the literature to use any X-ray characterized hetero-bimetallic CP for the fabrication of any optoelectronic devices till date. In this work, a compartmental Schiff base ligand has been used to synthesize a nickel(II) complex, which could then be used as a metalloligand to prepare a hetero-bimetallic nickel(II)/lead(II) building block, which in turn, is linked via thiocyanate to form a coordination polymer (Scheme 1$)$. The band gap $(3.18 \mathrm{eV})$ has been calculated from Tauc's plot, and it suggests the semiconducting nature of the complex. The rectifying nature in $I-V$ characteristics hints toward its Schottky diode characteristics. The on-off ratio (70) of the semiconductor device fabricated with CP is high. This is eventually the first report of any hetero-bimetallic coordination polymer with photosensitivity, which could be used in the fabrication of a Schottky diode.

\section{EXPERIMENTAL SECTION}

Nickel(II) thiocyanate tetrahydrate has been prepared by us following the literature method. ${ }^{15}$ Other reagents and solvents

Received: August 14, 2018

Accepted: September 21, 2018

Published: October 8, 2018 
Scheme 1. Schematic Representation for the Synthetic Route to the Complex

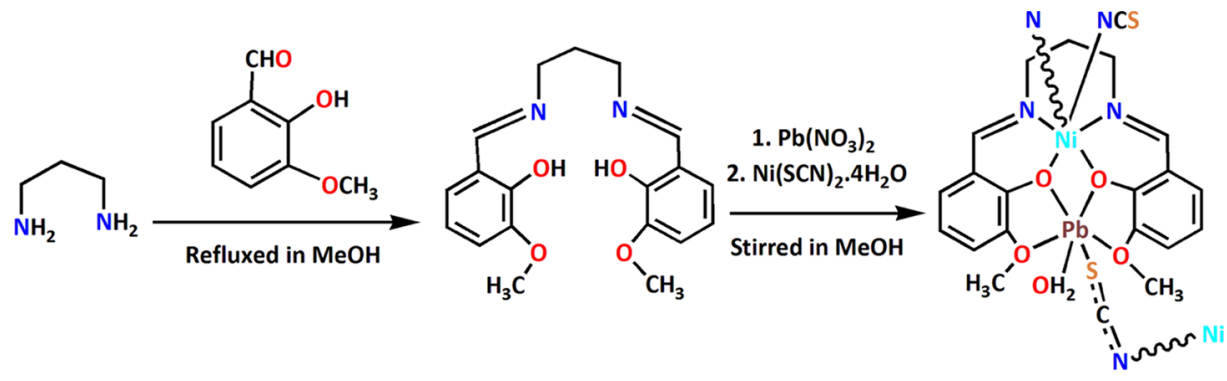

(AR grade) were used as procured from Sigma-Aldrich without purification.

Synthesis. Synthesis of $\mathrm{H}_{2} L \quad\left[N, N^{\prime}-B i s(3-\right.$ methoxysalicylidene)propane-1,3-diamine]. 3-Methoxysalicylaldehyde (304 mg, $2 \mathrm{mmol}$ ) and 1,3-diaminopropane $(0.13 \mathrm{~mL}, 1 \mathrm{mmol})$ were mixed in methanol $(20 \mathrm{~mL})$, and the mixture was refluxed for ca. $1 \mathrm{~h}$ to prepare $\mathrm{H}_{2} \mathrm{~L}$ via Schiff base condensation. The ligand was not isolated and was used directly for the synthesis of the complex in the next step.

Synthesis of $\left[(\mathrm{NCS}) \mathrm{Pb}\left(\mathrm{H}_{2} \mathrm{O}\right) \mathrm{LNi}(\mathrm{NCS})\right]_{n}$. A methanol (10 $\mathrm{mL})$ solution of lead(II) nitrate $(332 \mathrm{mg}, 1 \mathrm{mmol})$ was added to the methanol solution $(20 \mathrm{~mL})$ of $\mathrm{H}_{2} \mathrm{~L}$, and the resulting solution was stirred for $15 \mathrm{~min}$. A methanol $(10 \mathrm{~mL})$ solution of nickel(II) thiocyanate tetrahydrate $(250 \mathrm{mg}, 1 \mathrm{mmol})$ was then added to it, and the stirring was continued for about $2 \mathrm{~h}$. X-ray quality crystalline complexes were obtained after 3-4 days on slow evaporation of the solution in open atmosphere. Suitable single crystals were isolated from this product for Xray diffraction analysis.

Yield: $518 \mathrm{mg}$ (70\%). Anal. calcd for $\mathrm{C}_{21} \mathrm{H}_{22} \mathrm{~N}_{4} \mathrm{NiO}_{5} \mathrm{PbS}_{2}$ $(\mathrm{FW}=740.46): \mathrm{C}, 34.06 ; \mathrm{H}, 2.99 ; \mathrm{N}, 7.57$; found: $\mathrm{C}, 33.9 ; \mathrm{H}$, 2.8; N, 7.7\%. FT-IR $\left(\mathrm{KBr}, \mathrm{cm}^{-1}\right): 1635(\mathrm{C}=\mathrm{N}) ; 2112,2042$ $(\mathrm{C} \equiv \mathrm{N}) . \mathrm{UV}-$ vis $\left[\lambda_{\max }(\mathrm{nm})\right]\left[\varepsilon_{\max }\left(\mathrm{L} \mathrm{mol}^{-1} \mathrm{~cm}^{-1}\right)\right](\mathrm{DMF})$ : $271\left(1.7 \times 10^{4}\right) ; 352\left(8.6 \times 10^{3}\right) ; 584(9.5) ; 814(74.1)$.

Physical Measurements. $\mathrm{C}, \mathrm{H}$, and $\mathrm{N}$ analysis was performed using a PerkinElmer 240C elemental analyzer. IR spectrum in $\mathrm{KBr}\left(4500-500 \mathrm{~cm}^{-1}\right)$ was recorded with a PerkinElmer Spectrum Two spectrophotometer. Electronic spectrum of the complex in $\mathrm{N}, \mathrm{N}$-dimethylformamide (DMF) was recorded on a PerkinElmer Lambda 35 UV-visible spectrophotometer. Steady-state photoluminescence spectrum of the complex in DMF was obtained in Shimadzu RF-5301PC spectrofluorometer at room temperature. Time-dependent photoluminescence spectrum was recorded using a Hamamatsu MCP photomultiplier (R3809) and was analyzed by using IBHDAS6 software. X-ray diffraction of the powdered sample was performed on a Bruker D8 instrument with $\mathrm{Cu} \mathrm{K} \alpha$ radiation $(\lambda=1.5406 \AA)$.

X-ray Crystallography. A suitable single crystal of the complex was picked and mounted on a glass fiber, and diffraction intensities were measured with an Oxford Diffraction X-Calibur diffractometer equipped with Mo $\mathrm{K} \alpha$ radiation $(\lambda=0.71073 \AA, 50 \mathrm{kV}, 40 \mathrm{~mA})$ at $150 \mathrm{~K}$. Data collection and reduction were performed with the Crysalis software. ${ }^{16}$ The structure of the complex was solved by direct methods using SHELXS-97 and refined by full-matrix least squares on $F^{2}$, using the SHELXL-2016 program. ${ }^{17}$ Nonhydrogen atoms were refined anisotropically. Hydrogen atoms attached with oxygen atoms were located by difference Fourier maps. All other hydrogen atoms were placed in their geometrically idealized positions and constrained to ride on their parent atoms. Programs used included PLATON, ${ }^{18}$ DIAMOND, ${ }^{19}$ ORTEP, ${ }^{20}$ and MERCURY. ${ }^{21}$

Device Fabrication. Electrical characterization was performed in the complex-based metal-semiconductor (MS) junction devices. These devices were fabricated by depositing a thin film of a well-dispersed solution of the synthesized complex. To develop the thin films, indium tin oxide (ITO)coated glass substrates were cleaned by acetone, ethanol, and distilled water with the help of an ultrasonicator. Thereafter, the complex was separately mixed with $N, N$-dimethylformamide (DMF) in the right proportion $\left(20 \mathrm{mg} \mathrm{mL}^{-1}\right)$ and sonicated for several minutes until it produces a well-stabilized dispersion. Then, on the top of the cleaned ITO-coated substrates, stable dispersion of the just prepared complex was spun first at $600 \mathrm{rpm}$ for $4 \mathrm{~min}$ and thereafter at $1000 \mathrm{rpm}$ for 6 min with the help of SCU 2700 spin coating unit. To evaporate the solvent, as-deposited thin films were annealed under vacuum at $80{ }^{\circ} \mathrm{C}$ for $30 \mathrm{~min}$. For the characterization of the developed thin film, thickness was measured by a surface profiler as $\sim 1 \mu \mathrm{m}$. Pure $\mathrm{Al}(99.99 \%)$ was chosen as the metal electrode and was deposited on to the active thin film to prepare the metal-semiconductor (MS) interface through a shadow mask by thermal evaporation technique with the help of a vacuum-coating unit under a base pressure of $10^{-6}$ Torr. The effective areas of the films were maintained as $7.065 \times$ $10^{-2} \mathrm{~cm}^{-2}$. For electrical characterization of the devices, the current-voltage $(I-V)$ characteristics were recorded under dark and AM 1.5G radiation with the help of a Keithley 2635B source meter by a two-probe technique. All preparation and measurements were performed at room temperature and under ambient conditions.

\section{RESULTS AND DISCUSSION}

Synthesis. $\mathrm{H}_{2} \mathrm{~L}$ is a $\mathrm{N}_{2} \mathrm{O}_{2} \mathrm{O}_{2}{ }^{\prime}$ donor Schiff base ligand, and it has been prepared by refluxing 1,3-diaminopropane and 3methoxysalicylaldehyde in methanol following the literature method. ${ }^{22}$ The ligand $\left(\mathrm{H}_{2} \mathrm{~L}\right)$ on reaction with lead(II) nitrate followed by the addition of nickel(II) thiocyanate tetrahydrate formed the complex. Formation of the complex has been shown in Scheme 1.

Structure Description. $\left[(\mathrm{NCS}) \mathrm{Pb}\left(\mathrm{H}_{2} \mathrm{O}\right) \mathrm{LNi}(\mathrm{NCS})\right]_{n}$. The complex crystallizes in monoclinic Space group $P 21 / n$. Selected crystallographic data have been summarized in Table 1. Significant bond lengths and bond angles have been gathered in Tables 2 and S1 (Supporting Information), respectively.

The complex consists of a chain system with the repeating hetero-dinuclear neutral units, $\left[(\mathrm{NCS}) \mathrm{Pb}\left(\mathrm{H}_{2} \mathrm{O}\right) \mathrm{LNi}(\mathrm{NCS})\right]_{n}$, joined through two $\mu_{1,3}$-thiocyanate bridge. In each bimetallic unit, the nickel(II) and lead(II) centers, respectively, occupy 
Table 1. Crystal Data and Refinement Details

\begin{tabular}{|c|c|}
\hline formula & $\mathrm{C}_{21} \mathrm{H}_{22} \mathrm{~N}_{4} \mathrm{NiO}_{5} \mathrm{PbS}_{2}$ \\
\hline formula weight & 740.46 \\
\hline temperature $(\mathrm{K})$ & 150 \\
\hline crystal system & monoclinic \\
\hline space group & $P 21 / n$ \\
\hline$a(\AA)$ & $12.3716(6)$ \\
\hline$b(\AA)$ & $9.6865(3)$ \\
\hline$c(\AA)$ & $20.7826(13)$ \\
\hline$\beta\left({ }^{\circ}\right)$ & $105.941(6)$ \\
\hline$Z$ & 4 \\
\hline$d_{\text {calc }}\left(\mathrm{g} \mathrm{cm}^{-3}\right)$ & 2.054 \\
\hline$\mu\left(\mathrm{mm}^{-1}\right)$ & 8.022 \\
\hline$F(000)$ & 1432 \\
\hline total reflections & 15388 \\
\hline unique reflections & 6823 \\
\hline observed data $[I>2 \sigma(I)]$ & 5172 \\
\hline no. of parameters & 326 \\
\hline$R$ (int) & 0.051 \\
\hline$R_{1}, w R_{2}$ (all data) & $0.0798,0.0987$ \\
\hline$R_{1}, \mathrm{wR}_{2}[I>2 \sigma(I)]$ & $0.0538,0.0916$ \\
\hline
\end{tabular}

Table 2. Selected Bond Lengths ( $\AA$ ) of the Complex

\begin{tabular}{llll}
$\mathrm{Ni}(1)-\mathrm{O}(31)$ & $2.034(4)$ & $\mathrm{Pb}(1)-\mathrm{O}(11)$ & $2.328(4)$ \\
$\mathrm{Ni}(1)-\mathrm{N}(23)$ & $2.030(5)$ & $\mathrm{Pb}(1)-\mathrm{O}(131)$ & $2.655(6)$ \\
$\mathrm{Ni}(1)-\mathrm{N}(19)$ & $2.029(6)$ & $\mathrm{Pb}(1)-\mathrm{O}(31)$ & $2.310(4)$ \\
$\mathrm{Ni}(1)-\mathrm{O}(11)$ & $2.039(4)$ & $\mathrm{Pb}(1)-\mathrm{O}(291)$ & $2.645(6)$ \\
$\mathrm{Ni}(1)-\mathrm{N}(2)$ & $2.154(6)$ & $\mathrm{Pb}(1)-\mathrm{S}(1)$ & $2.867(2)$ \\
$\mathrm{Ni}(1)-\mathrm{N}(1)^{a}$ & $2.112(5)$ & $\mathrm{Pb}(1)-\mathrm{O}(1)$ & $2.703(7)$ \\
\multicolumn{5}{l}{} \\
\multicolumn{5}{l}{ ymmetry transformations $=1 / 2-x,-1 / 2+y, 1 / 2-z}$.
\end{tabular}

the inner $\mathrm{N}_{2} \mathrm{O}_{2}$ and outer $\mathrm{O}_{2} \mathrm{O}_{2}{ }^{\prime}$ sites of the potential $\mathrm{N}_{2} \mathrm{O}_{2} \mathrm{O}_{2}{ }^{\prime}$ donor deprotonated compartmental Schiff base, $\mathrm{L}^{2-}$. A perspective view of the asymmetric unit of the complex with selective atom numbering scheme is depicted in Figure 1. Both nickel(II) and lead(II) have pseudo octahedral geometries. $\mathrm{Ni}(1)$ is coordinated by two imine nitrogen atoms, $\mathrm{N}(19)$ and $\mathrm{N}(23)$, and two phenoxo oxygen atoms, $\mathrm{O}(11)$ and $\mathrm{O}(31)$, of the deprotonated potential $\mathrm{N}_{2} \mathrm{O}_{2} \mathrm{O}_{2}{ }^{\prime}$ donor compartmental Schiff base ligand $(\mathrm{L})^{2-}$, which constitute the equatorial plane. The deviation of the coordinating atoms $\mathrm{N}(19), \mathrm{N}(23)$,
$\mathrm{O}(11)$, and $\mathrm{O}(31)$ from the least-square mean plane through them is $-0.037(5), 0.038(5), 0.044(4)$, and $-0.043(4) \AA$, respectively, and that of $\mathrm{Ni}(1)$ from the same plane is $0.0025(7) \AA$. The fifth coordination site is occupied by one nitrogen atom, $\mathrm{N}(2)$, from a thiocyanate anion. A nitrogen atom, $\mathrm{N}(1)^{\#}$, from a symmetry-related $(1 / 2-x,-1 / 2+y, 1 / 2$ - z) thiocyanate anion coordinates nickel(II) in its sixth coordination site to form a distorted octahedron. On the other hand, lead(II) is coordinated by two phenoxo oxygen atoms, $\mathrm{O}(11)$ and $\mathrm{O}(31)$, and two ethoxy oxygen atoms, $\mathrm{O}(131)$ and $\mathrm{O}(291)$, which constitute the equatorial plane. The fifth coordination site is occupied by an oxygen atom, $\mathrm{O}(1)$, from a water molecule. A sulfur atom, S(1), from an end-to-end bridged thiocyanate coordinates with lead(II) in its sixth coordination site to complete its distorted octahedral geometry. Nickel(II) and lead(II) centers are bridged by two phenoxo oxygen atoms, $\mathrm{O}(11)$ and $\mathrm{O}(31)$, with $\mathrm{Ni}(1) \cdots \mathrm{Pb}(1)$ distance being $3.458(7) \AA$. The bridging angles, $\mathrm{Ni}(1)-$ $\mathrm{O}(11)-\mathrm{Pb}(1)$ and $\mathrm{Ni}(1)-\mathrm{O}(31)-\mathrm{Pb}(1)$, are $104.5(2)$ and $105.3(2)^{\circ}$, respectively. The $\mathrm{Ni}(1)-\mathrm{O}(11)-\mathrm{O}(31)-\mathrm{Pb}(1)$ core is almost planar (the dihedral angle is close to $\sim 5.32^{\circ}$ ).

Supramolecular Interaction. The complex forms an interesting supramolecular structure via $\pi \cdots \pi$ interactions. $\pi \cdots \pi$ interactions have been observed between the phenyl ring $\mathrm{C}(12)-\mathrm{C}(13)-\mathrm{C}(14)-\mathrm{C}(15)-\mathrm{C}(16)-\mathrm{C}(17)$ and symmetryrelated $(-x,-y,-z)$ phenyl ring $C(12)-C(13)-C(14)-$ $C(15)-C(16)-C(17)$. These interactions form a two-dimensional (2D) structure (Figure 2). Details of the geometric features of $\pi \cdots \pi$ interactions have been given in Table 3 .

Morphological Analysis. Microstructure of the complex has been studied by field emission scanning electron microscope (FESEM) and presented in Figure 3. The micrograph states featherlike morphology of the complex.

Optical Analysis. The Tauc plot (the details have been given in the Supporting Information) of the material has been presented in Figure 4. From Tauc's plot, the direct energy band gap $\left(E_{\mathrm{g}}\right)$ of the material has been estimated as $3.18 \mathrm{eV}$ by measuring the $x$-intercept of the extrapolated linear part of the plot $(\alpha h \nu)^{2}$ vs $(h \nu)$. The analysis for taking direct band gap has been provided in the Supporting Information.

As the band gap suggests that the complex is semiconducting in nature, there is a possibility to apply the complex in a

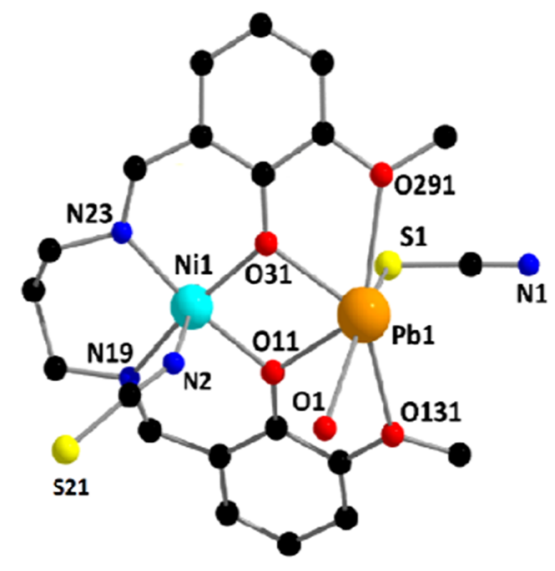

(a)

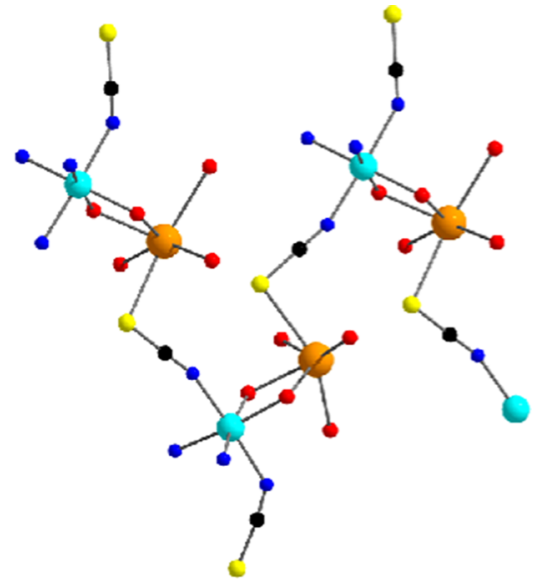

(b)

Figure 1. (a) Perspective view of the complex (asymmetric unit) with a selective atom numbering scheme; (b) the polymeric structure of the complex. Only the relevant atoms have been shown for clarity in both cases. 


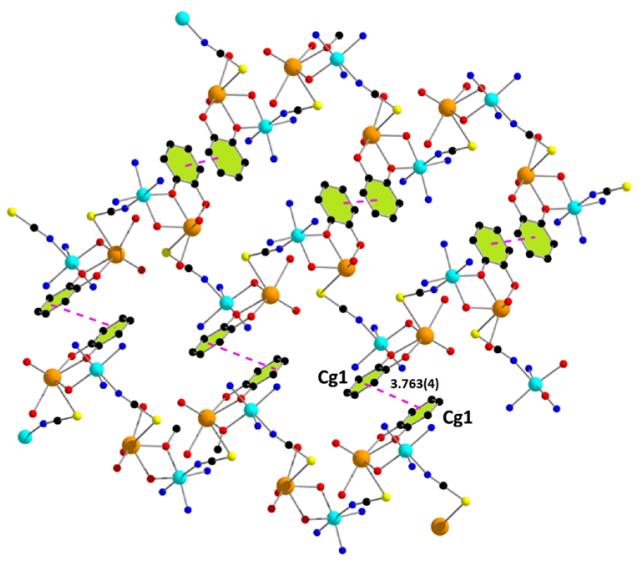

Figure 2. Perspective view of $2 \mathrm{D}$ structure formed by $\pi \cdots \pi$ interactions of the complex. Only the relevant atoms have been shown for clarity.

semiconducting device. But there has always been technological difficulty in application of these materials in active devices. Thus, to check the possibility of device application, fabrication of a metal-semiconductor-based thin-film Schottky diode has been tried. As the electronic charge transport properties determine the performance of the devices, it is very important to analyze charge transport properties in detail.

Electrical Characterization. The current-voltage $(I-V)$ measurements of the device [schematic diagram (Figure S2) has been given in the Supporting Information] fabricated with CP have been done in dark and under AM 1.5G light illumination in the voltage range of -2 to $+2 \mathrm{~V}$. Experimentally obtained $I-V$ curves of the device under dark and illumination are shown in Figure 5. The inset in Figure 5 represents the curve in log scale.

The nonlinear $I-V$ curve of the device under both the conditions indicates that the fabricated metal-semiconductor junction is a Schottky junction. From the $I-V$ curve, rectification ratios have been calculated, which are 70 and 89 under dark and illumination condition, respectively. This proves the successful application of the complex material in an active electronic device. The estimated conductivity of the thin film has been increased from $2.02 \times 10^{-4} \mathrm{~S} \mathrm{~cm}^{-1}$ under dark to $8.55 \times 10^{-4} \mathrm{~S} \mathrm{~cm}^{-1}$ under light. The conductivity data for the crystal has also been provided in the Supporting Information.

To assess the potentiality of the fabricated device for application in a photodetector, we have estimated important parameters like photosensitivity $\left(S=I_{\mathrm{ph}} / I_{\mathrm{D}}\right.$ where $I_{\mathrm{ph}}$ is the photocurrent and $I_{\mathrm{D}}$ is the dark current $\left.I_{\text {dark }}\right)$, specific detectivity $\left(D^{*}\right)$, and responsivity $(R)$. Photosensitivity of our device is 5.76, and this has been compared with the other reported devices and presented in Table $4 .^{23}$

Responsivity $(R)$ of the device can be estimated from the following equation

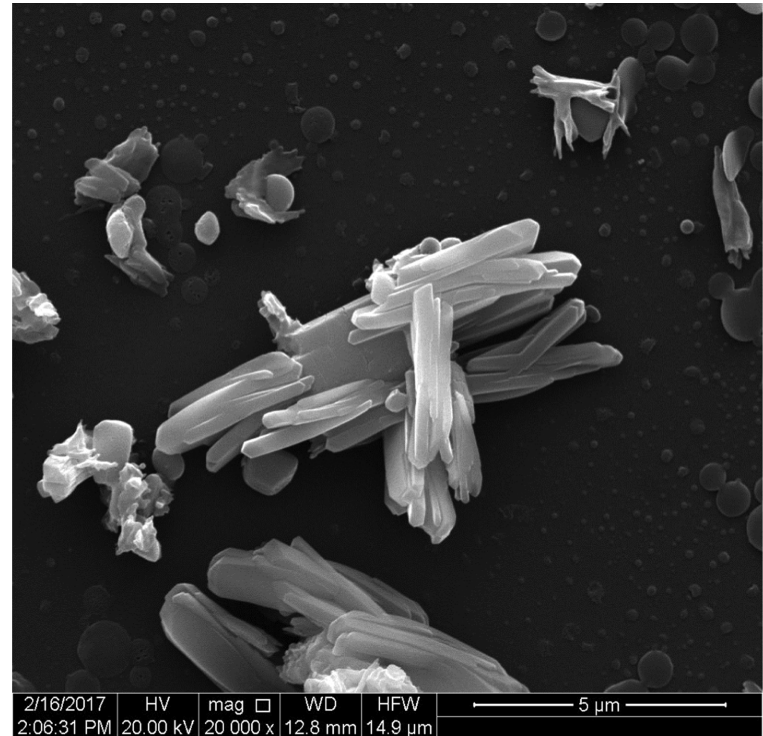

Figure 3. FESEM image of the complex.

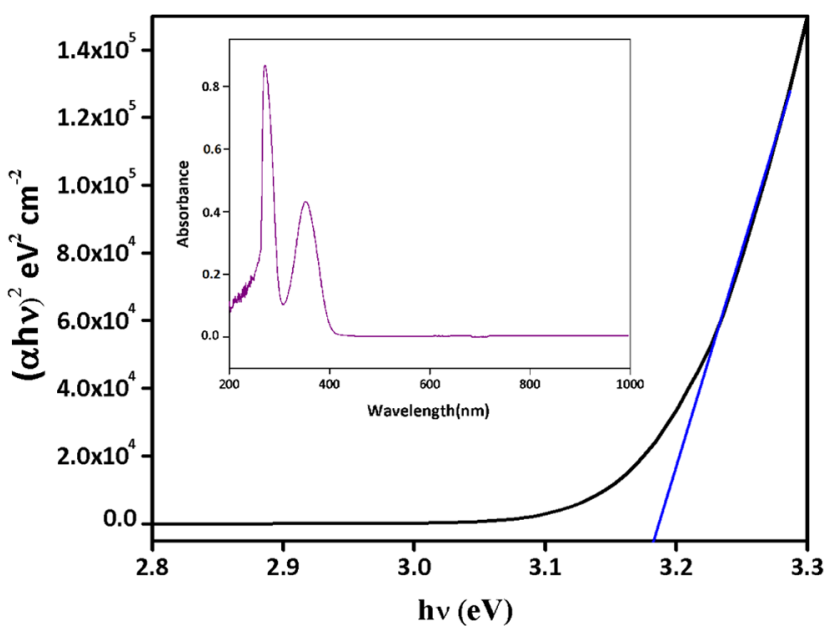

Figure 4. UV-vis absorption spectra (inset) and Tauc's plot for the complex.

$$
R=\frac{I_{\mathrm{ph}}}{P_{\mathrm{in}} A}
$$

Here, $A$ is the effective area of the diode and $P_{\text {in }}$ is the incident power of the light. For our device, the responsivity is $1.69 \mathrm{~A}$ $\mathrm{W}^{-1}$, which is significant for this kind of device. The specific detectivity $\left(D^{*}\right)$ has been estimated from the equation

$$
D^{*}=\frac{R}{\left(2 q I_{\mathrm{D}}\right)^{1 / 2}}
$$

where $q$ is the charge of electron. The specific detectivity of the device has been estimated as $6.55 \times 10^{10}$ Jones, which is again

Table 3. Geometric Features (Distances in $\AA$ and Angles in ${ }^{\circ}$ ) of the $\pi^{\cdots} \cdot \pi$ Interaction Obtained for the Complex

$\begin{array}{ccccc}\operatorname{Cg}(\text { ring I }) \cdots \operatorname{Cg}(\text { ring J }) & \operatorname{Cg} \cdots \operatorname{Cg}(\AA) & \alpha\left(^{\circ}\right) & \operatorname{Cg}(\mathrm{I}) \cdots \operatorname{perp}(\AA) & \operatorname{Cg}(\mathrm{J}) \cdots \operatorname{perp}(\AA) \\ \operatorname{Cg}(1) \cdots \operatorname{Cg}(1)^{a, b} & 3.763(4) & 0 & 3.471(3) & 3.471(3)\end{array}$

${ }^{a}$ Symmetry transformations $=-x,-y$, and $-z .{ }^{b} \alpha=$ Dihedral angle between ring I and ring J; $\mathrm{Cg}(\mathrm{I}) \cdots$ perp $=$ perpendicular distance of $\mathrm{Cg}(\mathrm{I})$ on ring J; $\mathrm{Cg}(\mathrm{I}) \cdots$ perp = perpendicular distance of $\mathrm{Cg}(\mathrm{J})$ on ring $\mathrm{I}$. $\mathrm{Cg}(1)=$ center of gravity of the ring $\mathrm{C}(12)-\mathrm{C}(13)-\mathrm{C}(14)-\mathrm{C}(15)-\mathrm{C}(16)-$ $\mathrm{C}(17)$, for the complex. 


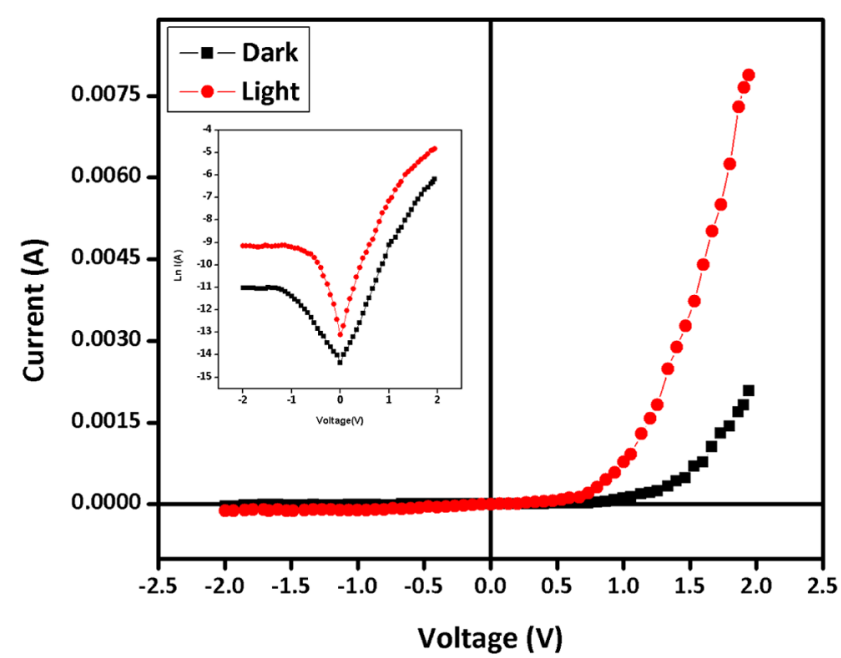

Figure 5. Current-voltage characteristics curve in dark and under light.

significant. All device parameters indicate that the fabricated device has a great potential in the field of active electronic device.

Further analysis of the different device parameters has been done by thermionic emission theory given by the following equation

$$
I=I_{0}\left[\exp \left(\frac{q V}{n K T}\right)-1\right]
$$

Here, the forward current is represented by $I$, reverse saturation current by $I_{0}, V$ denotes the applied bias voltage, $q$ is the electronic charge, $k$ represents the Boltzmann constant, $T$ gives the absolute temperature, and $n$ denotes the ideality factor (IF). $I_{0}$ is expressed by

$$
I_{0}=A A^{*} T^{2} \exp \left(\frac{-q \varphi_{\mathrm{B}}}{K T}\right)
$$

The effective area of the diode $(A)$ is taken to be $7.065 \times 10^{-2}$ $\mathrm{cm}^{2}, A^{*}$ denotes the Richardson constant whose value is $32 \mathrm{~A}$ $\mathrm{K}^{-2} \mathrm{~cm}^{-1}$, and $\phi_{\mathrm{B}}$ is the Schottky barrier height.

By using following Cheung's equations ${ }^{24}$ given below, other different Schottky parameters have also been calculated

$$
\frac{\mathrm{d} V}{\mathrm{~d} \ln I}=\left(\frac{\eta k T}{q}\right)+I R_{\mathrm{S}}
$$

$$
\begin{aligned}
& H(I)=V-\frac{\eta k T}{q} \ln \left(\frac{I}{A A^{*} T^{2}}\right) \\
& H(I)=I R_{\mathrm{S}}+\eta \phi_{\mathrm{B}}
\end{aligned}
$$

Here, the series resistance is given by $R_{\mathrm{S}}$ and all other notations are kept same.

The intercept of the $\mathrm{d} V / \mathrm{d} \ln I$ vs $I$ plot shown in Figure 6 is used to estimate the ideality factor. Determination of the barrier potential height and the series resistance is done using the intercept and slope of $H(I)$ vs $I$ plot given in Figure 7. The various parameters calculated are enlisted in Table 5 .

The ideality factor should be unity, but here it is less than 1 , which can be due to the presence of inhomogeneities at the Schottky junction. ${ }^{25}$

For the assessment of charge transport behavior of the device, mobility and diffusion length of charge carriers are the two important parameters. So the charge transport mechanism has been analyzed through the metal-semiconductor contact. Here, we have estimated mobility $\left(\mu_{\text {eff }}\right)$, lifetime $(\tau)$, carrier concentration $(N)$, and diffusion length $\left(L_{\mathrm{D}}\right)$ by applying space charge limited current (SCLC) theory. Figure 8 shows the $I-V$ curve in a double logarithmic scale. The graph presented in Figure 8 can be divided into three regions with different slopes. Region 1 (Reg 1), which represents the lower bias, follows ohmic nature with current being directly proportional to voltage. The origin of the current is from the bulk generated electrons of the film, rather than the injected free carriers. Here, tunneling is the main contributing factor that can be observed from the $I-V$ curve. $^{26}$

In Figure 8, the slope of Reg 2 is increased compared with Reg 1 . Within the material, a part of the injected carriers is trapped within the traps present and a part remains free. With the increase of applied voltage, traps within the material are filled with a higher number of injected carriers. ${ }^{27}$ As the current increases rapidly, the Fermi level $\left(E_{\mathrm{F}}\right)$ moves through a trap level. ${ }^{28}$ The slope of this region increases sharply as the traps are being filled up rapidly by the carriers. The second region is known as the trap filling region. ${ }^{28}$ When almost all traps are filled, the slope of the third region decreases as result of slower carrier movement. Here, current follows the relationship $I \propto V^{2}$, which is the feature of trap-free space charge limited current (SCLC) regime. ${ }^{27,28}$

So, effective carrier mobility $\left(\mu_{\text {eff }}\right)$ has been estimated from $I$ vs $V^{2}$ graph (Figure 9) of the trap-free SCLC region using the Mott-Gurney equation ${ }^{29}$ given by

Table 4. Previously Reported X-ray Characterized Photosensitive Complexes ${ }^{a}$

\begin{tabular}{lcccc}
\multicolumn{1}{c}{ complex } & conductivity in dark & conductivity under light & photosensitivity & ref \\
{$\left[\mathrm{CdL}^{1}\left(\mu_{1,3}-\mathrm{SCN}\right)_{2}\right]_{n}$} & $1.01 \times 10^{-8}$ & $2.16 \times 10^{-8}$ & 14.36 & $23 \mathrm{a}$ \\
{$\left[\mathrm{Cu}_{2}(\mathrm{adc})(4-\mathrm{pic})_{6}\left(\mathrm{H}_{2} \mathrm{O}\right)_{4}\right]\left[\mathrm{ClO}_{4}\right]_{2}$} & $8.21 \times 10^{-4}$ & $11.84 \times 10^{-4}$ & 1.83 & $23 \mathrm{~b}$ \\
$\left\{\left[\mathrm{Zn}(\mathrm{adc})(4-\mathrm{spy})_{2}\left(\mathrm{H}_{2} \mathrm{O}\right)_{2}\right]\right\}_{n}$ & $5.12 \times 10^{-4}$ & $16.48 \times 10^{-4}$ & $1.96-2$ & $23 \mathrm{c}$ \\
$\left\{\left[\mathrm{Cd}(\mathrm{adc})(4-\mathrm{spy})_{2}-\left(\mathrm{H}_{2} \mathrm{O}\right)_{2}\right]\right\}_{n}$ & $6.54 \times 10^{-4}$ & $28.77 \times 10^{-4}$ & 3.5 & $23 \mathrm{c}$ \\
{$\left[\mathrm{Cd}\left(2,2^{\prime}-\mathrm{dsb}\right)(4-\mathrm{nvp})(\mathrm{DMF})\left(\mathrm{H}_{2} \mathrm{O}\right)\right]$} & $6.60 \times 10^{-4}$ & $10.71 \times 10^{-4}$ & 0.54 & $23 \mathrm{~d}$ \\
{$\left[\mathrm{Cu}_{2}\left(\mathrm{~L}^{1}\right)_{2}\left(\mu-1,3^{-} \mathrm{SCN}\right)_{2}\right]_{n}$} & $3.63 \times 10^{-5}$ & $4.13 \times 10^{-5}$ & 2.83 & $23 \mathrm{e}$ \\
{$\left[\{\mathrm{CuLNa}\}_{2}\left(\mu_{1,1,3}-\mathrm{NCS}\right) \mathrm{HgCl}\left(\mu_{1,3}-\mathrm{NCS}\right)\right]_{n}$} & $1.48 \times 10^{-6}$ & $8.40 \times 10^{-5}$ & 57 & $23 \mathrm{f}$ \\
{$\left[(\mathrm{NCS}) \mathrm{Pb}\left(\mathrm{H}_{2} \mathrm{O}\right) \mathrm{LNi}(\mathrm{NCS})\right]_{n}$} & $6.02 \times 10^{-6}$ & $3.47 \times 10^{-5}$ & 5.76 & this work
\end{tabular}

${ }^{a}$ Where $\mathrm{HL}^{1}=$ 2-(2-(ethylamino)ethyliminomethyl)-6-ethoxyphenol, $\mathrm{H}_{2}$ adc = acetylenedicarboxylic acid, 4-pic = 4-picolene, 4-spy = 4styrylpyridine, $\mathrm{H}_{2} 2,2^{\prime}$-dsb = 2,2' -disulfanediyldibenzoic acid (2,2'-dsba), and 4-nvp = 4-(1-naphthylvinyl)pyridine. 

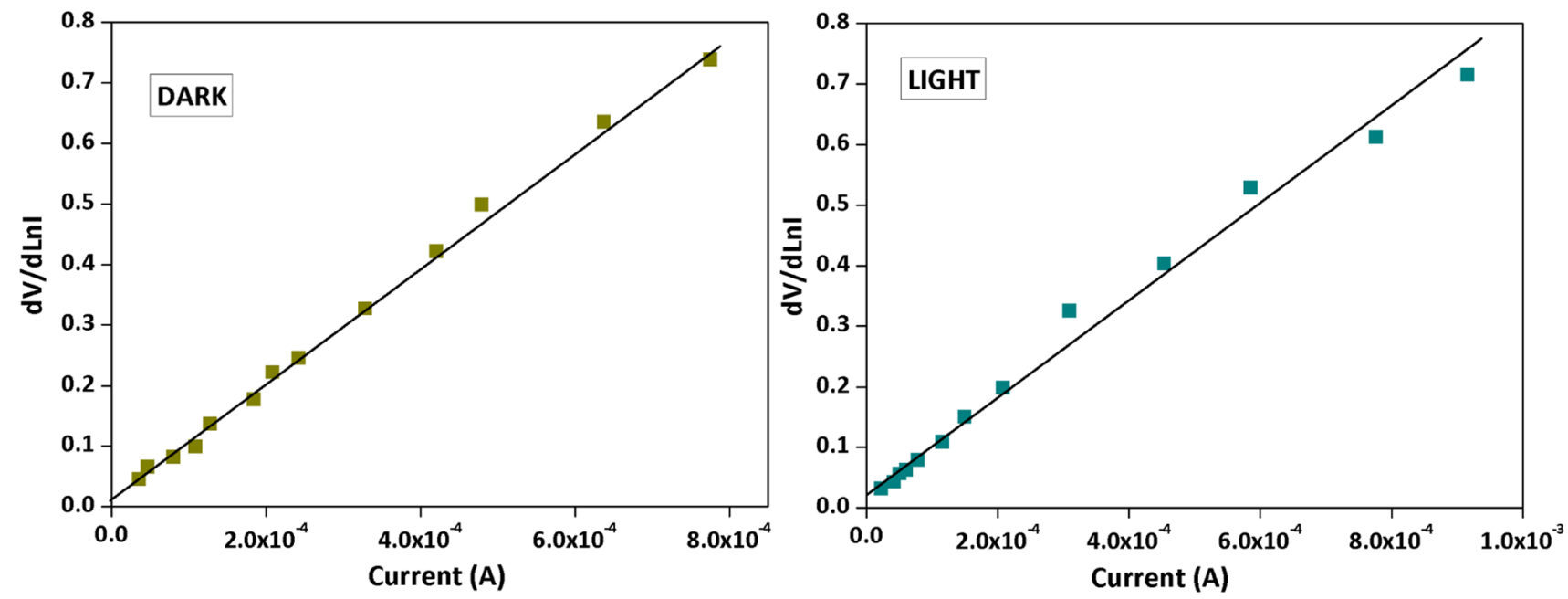

Figure 6. $\mathrm{d} V / \mathrm{d} \ln I$ vs current plot in dark and light conditions.
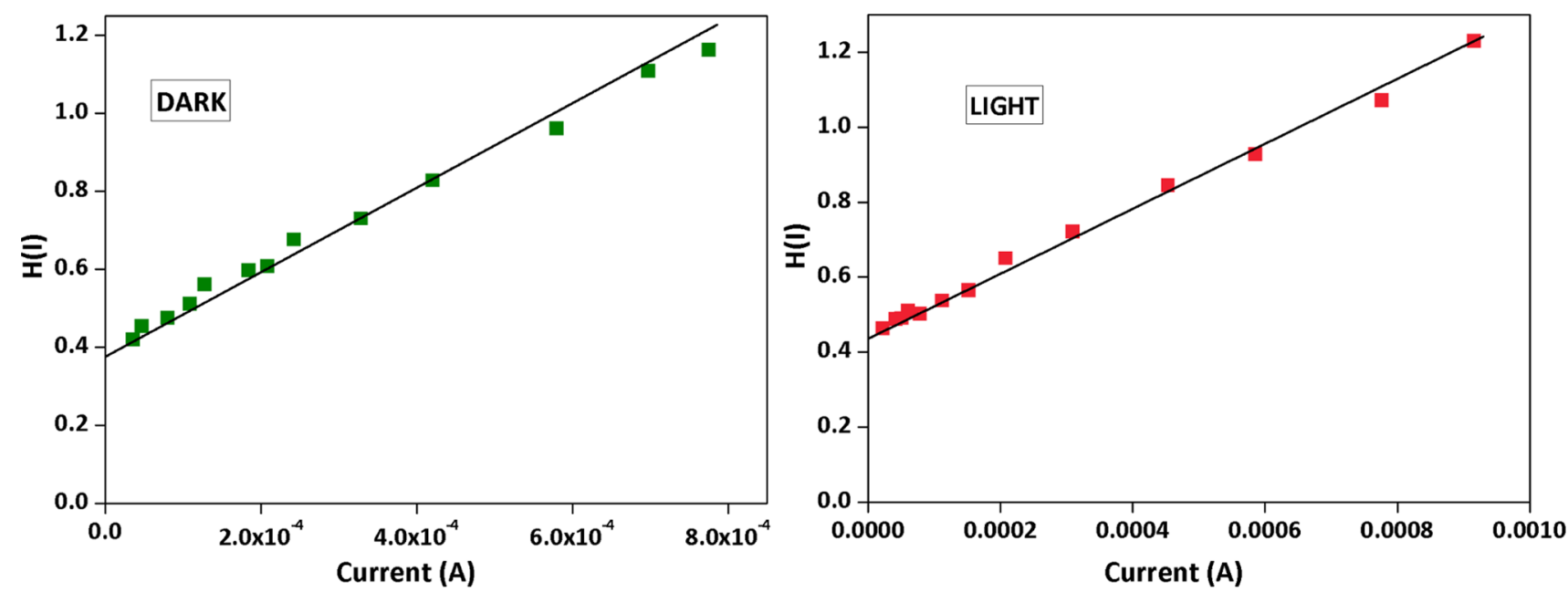

Figure 7. $H$ vs current graph in dark and light conditions.

Table 5. Different Charge Transport and Device-Related Parameters

\begin{tabular}{|c|c|c|c|c|c|c|c|c|c|c|c|}
\hline \multirow[b]{2}{*}{ conditions } & \multirow[b]{2}{*}{ on/off ratio } & \multirow[b]{2}{*}{$\sigma\left(\mathrm{S} \mathrm{cm}^{-1}\right)$} & \multirow[b]{2}{*}{ IF } & \multicolumn{2}{|c|}{$R_{\mathrm{S}}(\mathrm{k} \Omega)$} & \multirow[b]{2}{*}{$\Phi_{\mathrm{B}}(\mathrm{eV})$} & \multirow[b]{2}{*}{$\mu_{\text {eff }}\left(\mathrm{cm}^{2} \mathrm{~V}^{-1} \mathrm{~s}^{-1}\right)$} & \multirow[b]{2}{*}{$\mathrm{N}\left(\mathrm{m}^{-3}\right) \times 10^{23}$} & \multirow[b]{2}{*}{$\tau(\mu \mathrm{s})$} & \multirow[b]{2}{*}{$D\left(\mathrm{~m}^{2} \mathrm{~s}^{-1}\right) \times 10^{-8}$} & \multirow[b]{2}{*}{$\begin{array}{c}L_{\mathrm{D}} \\
(\mathrm{nm})\end{array}$} \\
\hline & & & & $\mathrm{d} V / \mathrm{d} \ln I$ & $H(I)$ & & & & & & \\
\hline dark & 70 & $2.02 \times 10^{-4}$ & 0.52 & 0.94 & 1.07 & 0.71 & $9.46 \times 10^{-3}$ & 1.33 & 0.35 & 8.85 & 248 \\
\hline light & 89 & $8.55 \times 10^{-4}$ & 0.79 & 0.80 & 0.86 & 0.55 & $3.42 \times 10^{-2}$ & 1.56 & 0.11 & 2.45 & 273 \\
\hline
\end{tabular}

$$
I=\frac{9 \mu_{\mathrm{eff}} \varepsilon_{0} \varepsilon_{\mathrm{r}} A V^{2}}{8 d^{3}}
$$

where $I$ is the current, $\varepsilon_{0}$ is the permittivity of free space, $\varepsilon_{\mathrm{r}}$ is the dielectric constant, and $d$ is the thickness of the film (about $1 \mu \mathrm{m})$.

There are few more important charge transport parameters like carrier concentration and transit time, which determine the device performance. The carrier concentration $(N)$, transit time $(\tau)$, and diffusion length $\left(L_{\mathrm{D}}\right)$ is estimated with the following set of equations ${ }^{30}$

$$
\begin{aligned}
& N=\frac{\sigma}{q \mu_{\mathrm{eff}}} \\
& \tau=\frac{9 \varepsilon_{0} \varepsilon_{\mathrm{r}} A}{8 d}\left(\frac{V}{I}\right)
\end{aligned}
$$

where $D$ is the diffusion coefficient. The diffusion coefficient has been calculated by employing the Einstein-Smoluchowski equation $^{31}$

$$
\mu_{\mathrm{eff}}=\frac{q D}{k T}
$$

By analyzing the charge transport parameters, it is seen that the diffusion length and carrier mobility increased and transit time decreased after light illumination, which indicates that the device could be very useful for photosensitive device applications.

\section{CONCLUSIONS}

Although the nonlinear rectifying behavior of $I-V$ characteristics of few semiconducting material-based devices measured under dark and illumination conditions proves their photo- 


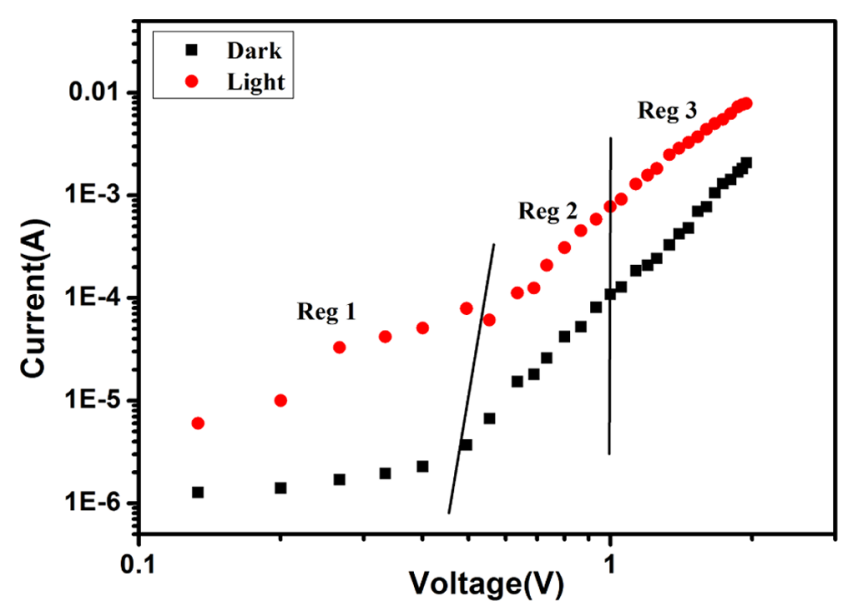

Figure 8. $I$ vs $V$ graph in double logarithmic scale.

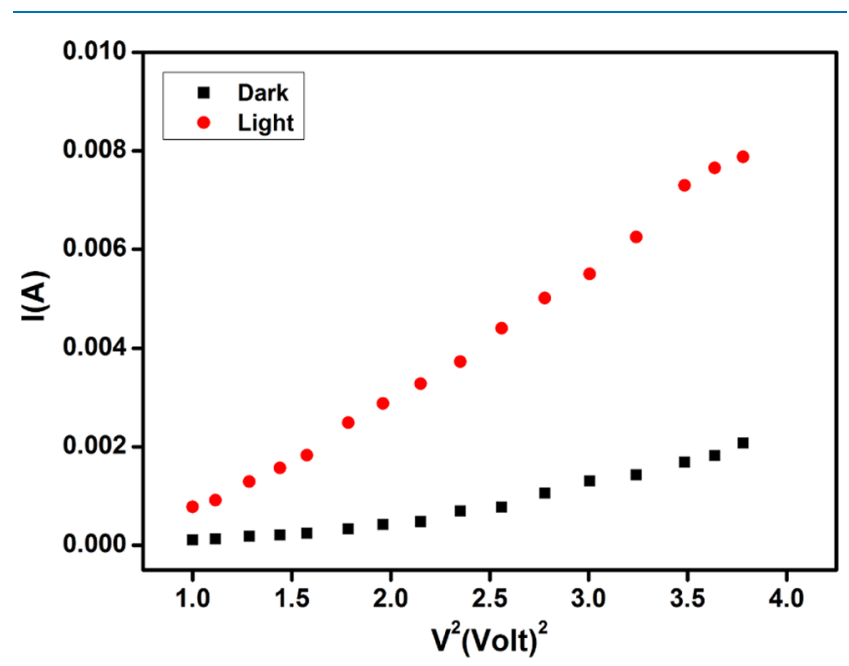

Figure 9. $I$ versus $V^{2}$ plot under dark and light.

sensitive Schottky diode character, there was no report in the literature to use any X-ray-characterized hetero-bimetallic coordination polymer for the fabrication of any optoelectronic device before the present work. In this article, synthesis, X-ray structure, and electronic properties of a hetero-bimetallic nickel(II)/lead(II) CP has been described. The band gap (3.18 $\mathrm{eV}$ ) of the material indicates that it belongs to the semiconductor family. Intermolecular interactions play a key role for molecular conductors and semiconductors. The present complex forms a one-dimensional (supramolecular) structure via coordinate bond. This coordinate bond formation helps the complex to show very high conductivity. The complex has been successfully applied in technologically challenging thin-film Schottky diodes with appraised different charge transport and device related parameters. The results indicate that the material can be applied to photosensitive active devices. The preparation of the complex thus illustrates a potentially versatile approach to the construction of heterobimetallic coordination polymers and their potential application in the field of optoelectronics.

We are still working in the laboratory to get better yield of the product and to develop and characterize more systems based on this strategy to generalize the concept.

\section{ASSOCIATED CONTENT}

\section{S Supporting Information}

The Supporting Information is available free of charge on the ACS Publications website at DOI: 10.1021/acsomega.8b02025.

Crystallographic data (CIF)

Optical analysis; conductivity of the crystal; dielectric measurements; IR, UV-vis, and fluorescence spectra; PXRD; thermogravimetric analysis; plot of $\mathrm{d}[\ln (\alpha h \nu)] /$ $\mathrm{d}(h \nu)$ vs $h \nu$ and plot of $\ln (\alpha h \nu)$ vs $\ln \left(h \nu-E_{\mathrm{g}}\right)$ (Figure S1); selected bond angles $\left({ }^{\circ}\right)$ of the complex (Table S1) (PDF)

\section{Accession Codes}

CCDC 1832205 contains the supplementary crystallographic data for this paper.

\section{AUTHOR INFORMATION}

\section{Corresponding Authors}

*E-mail: partha@phys.jdvu.ac.in (P.P.R.).

*E-mail: shouvik.chem@gmail.com. Tel: +9133-2457-2941

(S.C.).

ORCID

Partha Pratim Ray: 0000-0003-4616-2577

Shouvik Chattopadhyay: 0000-0001-7772-9009

Notes

The authors declare no competing financial interest.

\section{ACKNOWLEDGMENTS}

S.R. thanks UGC for providing fellowship. S.C. acknowledges the UGC-CAS II programme, Department of Chemistry, Jadavpur University, for funding under the head [Chemicals/ Consumables/Glassware].

\section{REFERENCES}

(1) (a) Batten, S. R.; Neville, S. M.; Turner, D. R. Coordination Polymers: Design, Analysis and Application; Royal Society of Chemistry: London, 2009; (b) Metal-Organic Frameworks. Applications from Catalysis to Gas Storage; Farrusseng, D., Ed.; Wiley-VCH Verlag GmbH: Weinheim, 2011. (c) Katsenis, A. D.; Brechin, E. K.; Papaefstathiou, G. S. Metal-Organic Framework Materials; MacGillivray, L. R., Lukehart, C. M., Eds.; John Wiley and Sons: U.K., 2014. (d) Janiak, C.; Vieth, J. K. MOFs, MILs and more: concepts, properties and applications for porous coordination networks (PCNs). New J. Chem. 2010, 34, 2366-2388. (e) Biradha, K.; Su, C.-Y.; Vittal, J. J. Recent Developments in Crystal Engineering. Cryst. Growth Des. 2011, 11, 875-886. (f) O'Keeffe, M.; Yaghi, O. M. Deconstructing the Crystal Structures of Metal-Organic Frameworks and Related Materials into Their Underlying Nets. Chem. Rev. 2012, 112, 675-702. (g) Kitagawa, S.; Kitaura, R.; Noro, S.-I. Functional Porous Coordination Polymers. Angew. Chem., Int. Ed. 2004, 43, 2334-2375. (h) Luo, G.-G.; Xiong, H.-B.; Dai, J.-C. Syntheses, Structural Characterization, and Properties of $\left\{\left[\mathrm{Cu}(\mathrm{bpp})_{2}\left(\mathrm{H}_{2} \mathrm{O}\right)_{2}\right]-\right.$ (tp) $\left.\cdot 7 \mathrm{H}_{2} \mathrm{O}\right\}$ and $\left\{\left[\mathrm{Cu}(\mathrm{bpp})_{2}\left(\mathrm{H}_{2} \mathrm{O}\right)\right](\mathrm{ip}) \cdot 7 \mathrm{H}_{2} \mathrm{O}\right\}$ Complexes. New Examples of the Organic Anionic Template Effect on Induced Assembly of Water Clusters (bpp $=1,3-B i s(4-p y r i d y l)$ propane, $\mathrm{tp}=$ Terephthalate, ip = Isophthalate). Cryst. Growth Des. 2011, 11, 507515. (i) Luo, G.-G.; Wu, D.-L.; Wu, J.-H.; Xia, J.-X.; Liu, L.; Dai, J.-C. Direct observation of conformational change of adipate dianions encapsulated in water clusters. CrystEngComm 2012, 14, 5377-5380.

(2) (a) Teufel, J.; Oh, H.; Hirscher, M.; Wahiduzzaman, M.; Zhechkov, L.; Kuc, A.; Heine, T.; Denysenko, D.; Volkmer, D. MFU4 - A Metal-Organic Framework for Highly Effective $\mathrm{H}_{2} / \mathrm{D}_{2}$ Separation. Adv. Mater. 2013, 25, 635-639. (b) Bhattacharya, B.; Ghoshal, D. Selective carbon dioxide adsorption by mixed-ligand 
porous coordination polymers. CrystEngComm 2015, 17, 8388-8413. (c) Gole, B.; Bar, A. K.; Mallick, A.; Banerjee, R.; Mukherjee, P. S. An electron rich porous extended framework as a heterogeneous catalyst for Diels-Alder reactions. Chem. Commun. 2013, 49, 7439-7441. (d) Feyand, M.; Mugnaioli, E.; Vermoortele, F.; Bueken, B.; Dieterich, J. M.; Reimer, T.; Kolb, U.; Vos, D.; de Stock, N. Automated Diffraction Tomography for the Structure Elucidation of Twinned, Sub-micrometer Crystals of a Highly Porous, Catalytically Active Bismuth Metal-Organic Framework. Angew. Chem., Int. Ed. 2012, 51, 10373-10376. (e) Horcajada, P.; Gref, R.; Baati, T.; Allan, P. K.; Maurin, G.; Couvreur, P.; Féerey, G.; Morris, R. E.; Serre, C. Metal-Organic Frameworks in Biomedicine. Chem. Rev. 2012, 112, 1232-1268. (f) Kundu, T.; Mitra, S.; Patra, P.; Goswami, A.; Díaz Díaz, D.; Banerjee, R. Mechanical Downsizing of a Gadolinium(III)based Metal-Organic Framework for Anticancer Drug Delivery. Chem. - Eur. J. 2014, 20, 10514-10518. (g) Kreno, L. E.; Leong, K.; Farha, O. K.; Allendorf, M.; Van Duyne, R. P.; Hupp, J. T. MetalOrganic Framework Materials as Chemical Sensors. Chem. Rev. 2012, 112, 1105-1125. (h) Heine, J.; Müller-Buschbaum, K. Engineering metal-based luminescence in coordination polymers and metalorganic frameworks. Chem. Soc. Rev. 2013, 42, 9232-9242. (i) Ma, L.; Evans, O. R.; Foxman, B. M.; Lin, W. Luminescent Lanthanide Coordination Polymers. Inorg. Chem. 1999, 38, 5837-5840. (j) Haldar, R.; Matsuda, R.; Kitagawa, S.; George, S. J.; Maji, T. K. Amine-Responsive Adaptable Nanospaces: Fluorescent Porous Coordination Polymer for Molecular Recognition. Angew. Chem., Int. Ed. 2014, 53, 11772-11777.

(3) (a) Najafi, E.; Amini, M. M.; Mohajerani, E.; Janghouri, M.; Razavi, H.; Khavasi, H. Fabrication of an organic light-emitting diode (OLED) from a two-dimensional lead(II) coordination polymer. Inorg. Chim. Acta 2013, 399, 119-125. (b) Evans, R. C.; Douglas, P.; Winscom, C. J. Coordination complexes exhibiting room-temperature phosphorescence: Evaluation of their suitability as triplet emitters in organic light emitting diodes. Coord. Chem. Rev. 2006, 250, 20932126.

(4) (a) Wu, G.; Huang, J.; Zang, Y.; He, J.; Xu, G. Porous FieldEffect Transistors Based on a Semiconductive Metal-Organic Framework. J. Am. Chem. Soc. 2017, 139, 1360-1363. (b) Chen, W.; Yuan, H.-M.; Wang, J.-Y.; Liu, Z.-Y.; Xu, J.-J.; Yang, M.; Chen, J.S. Synthesis, Structure, and Photoelectronic Effects of a UraniumZinc-Organic Coordination Polymer Containing Infinite Metal Oxide Sheets. J. Am. Chem. Soc. 2003, 125, 9266-9267.

(5) (a) Xu, H.; Chen, R.; Sun, Q.; Lai, W.; Su, Q.; Huang, W.; Liu, $\mathrm{X}$. Recent progress in metal-organic complexes for optoelectronic applications. Chem. Soc. Rev. 2014, 43, 3259-3302. (b) Seco, J. M.; Rodriguez-Dieguez, A.; Padro, D.; Garcia, J. A.; Ugalde, J. M.; Sebastian, E. S.; Cepeda, J. Experimental and Theoretical Study of a Cadmium Coordination Polymer Based on Aminonicotinate with Second-Timescale Blue/Green Photoluminescent Emission. Inorg. Chem. 2017, 56, 3149-3152.

(6) (a) Kaur, R.; Kim, K.-H; Paul, A. K.; Deep, A. Recent advances in the photovoltaic applications of coordination polymers and metal organic frameworks. J. Mater. Chem. A 2016, 4, 3991-4002. (b) Duprez, V.; Biancardo, M.; Spanggaard, H.; Krebs, F. C. Synthesis of conjugated polymers containing terpyridine-ruthenium complexes: Photovoltaic applications. Macromolecules 2005, 38, 10436-10448.

(7) (a) Liu, M.; Quah, H. S.; Wen, S.; Wang, J.; Kumar, P. S.; Eda, G.; Vittal, J. J.; Ji, W. Nonlinear optical properties of a onedimensional coordination polymer. J. Mater. Chem. C 2017, 5, 29362941. (b) Evans, O. R.; Lin, W. Crystal Engineering of Nonlinear Optical Materials Based on Interpenetrated Diamondoid Coordination Networks. Chem. Mater. 2001, 13, 2705-2712. (c) Stavila, V.; Talin, A. A.; Allendorf, M. D. MOF-based electronic and optoelectronic devices. Chem. Soc. Rev. 2014, 43, 5994-6010.

(8) (a) Andruh, M. Compartmental Schiff-base ligands-a rich library of tectons in designing magnetic and luminescent materials. Chem. Commun. 2011, 47, 3025-3042. (b) Black, D.; Blake, A. J.; Finn, R. L.; Lindoy, L. F.; Nezhadali, A.; Rougnaghi, G.; Tasker, P. A.;
Schröder, M. Compartmental Schiff-base ligands as selective doubleloaded extractants for copper(II). Chem. Commun. 2002, 340-341.

(9) (a) Sun, H.-L.; Wang, Z.-M; Gao, S. Synthesis, Crystal Structures, and Magnetism of Cobalt Coordination Polymers Based on Dicyanamide and Pyrazine-dioxide Derivatives. Inorg. Chem. 2005, 44, 2169-2176. (b) Roy, S.; Bhattacharyya, A.; Purkait, S.; Bauzá, A.; Frontera, A.; Chattopadhyay, S. A combined experimental and computational study on supramolecular assemblies in heterotetranuclear nickel(II)/cadmium(II) complexes with $\mathrm{N}_{2} \mathrm{O}_{4}$-donor compartmental Schiff bases. Dalton Trans. 2016, 45, 15048-15059.

(10) (a) James, T. L.; Smith, D. M.; Holm, R. H. Stereoelectronic Preferences in Electron Transfer Series of Nickel with Tridentate Ligands Containing Hard-Soft Donor Sets. Inorg. Chem. 1994, 33, 4869-4877. (b) Kruger, H.-J.; Holm, R. H. Stabilization of trivalent nickel in tetragonal $\mathrm{NiS}_{4} \mathrm{~N}_{2}$ and $\mathrm{NiN}_{6}$ environments: synthesis, structures, redox potentials and observations related to $[\mathrm{NiFe}]$ hydrogenases. J. Am. Chem. Soc. 1990, 112, 2955-2963. (c) Masgood, M. A.; Hodgson, D. J. Five- and Six-Coordinate Nickel(II) Complexes of New Multidentate Ligands Containing 2,9-Disubstituted-1,10Phenanthroline and Pyrazolyl Units. Inorg. Chem. 1994, 33, 30383042. (d) Lovecchio, F. V.; Gore, E. S.; Busch, D. H. Oxidation and reduction behavior of macrocyclic complexes of nickel. Electrochemical and electron spin resonance studies. J. Am. Chem. Soc. 1974, 96, 3109-3118. (e) Musker, W. K.; Hussain, M. S. Medium-ring complexes. III. Comparison of planar and pyramidal copper(II) and planar nickel(II) complexes containing seven- and eight-memberedring diamines. Inorg. Chem. 1969, 8, 528-536.

(11) (a) Gourlaouen, C.; Parisel, O.; Gerard, H. Revisiting the holoand hemidirected structural transition within the $\left[\mathrm{Pb}(\mathrm{CO})_{n}\right]^{2+}$ model series using first-principles Molecular Dynamics. Dalton Trans. 2011, 40, 11282-11288. (b) Shimoni-Livny, L.; Glusker, J. P.; Bock, C. W. Lone Pair Functionality in Divalent Lead Compounds. Inorg. Chem. 1998, 37, 1853-1867. (c) Davidovich, R. L.; Stavila, V.; Marinin, D. V.; Voit, E. I.; Whitmire, K. H. Stereochemistry of lead(II) complexes with oxygen donor ligands. Coord. Chem. Rev. 2009, 253, 1316-1352. (d) Davidovich, R. L.; Stavila, V.; Whitmire, K. H. Stereochemistry of lead(II) complexes containing sulfur and selenium donor atom ligands. Coord. Chem. Rev. 2010, 254, 2193-2226. (e) Holloway, C. E.; Melnik, M. Lead coordination and organometallic compounds: Classification and analysis of crystallographic and structural data. Main Group Met. Chem. 1997, 20, 399-495. (f) Parr, J. Some recent coordination chemistry of lead(II). Polyhedron 1997, 16, 551-566. (g) Parr, J. Germanium, Tin, and Lead, in Comprehensive Coordination Chemistry II; Elsevier: Oxford, 2004; Vol. 3, p 545. (h) Hino, S.; Brynda, M.; Phillips, A. D.; Power, P. P. Synthesis and Characterization of a Quasi-One Coordinate Lead Cation. Angew. Chem., Int. Ed. 2004, 43, 2655-2658. (i) Imran, M.; Mix, A.; Neumann, B.; Stammler, H.-G.; Monkowius, U.; Gründlinger, P.; Mitzel, N. W. Hemi- and holo-directed lead(II) complexes in a soft ligand environment. Dalton Trans. 2015, 44, 924-937.

(12) (a) Harrison, R. M.; Laxen, D. R. H. Lead Pollution, Chapman \& Hall: London, 1981. (b) Christensen, J. M.; Kristiansen, J. In Handbook of Metals in Clinical and Analytical Chemistry; Seiler, H. G., Sigel, A., Sigel, H., Eds.; Marcel Dekker: NY, 1994; pp 425-440. (c) Lanphear, B. P.; Burgoon, D. A.; Rust, S. W.; Eberly, S.; Galke, W. Environmental Exposures to Lead and Urban Children's Blood Lead Levels. Environ. Res. 1998, 76, 120-130. (d) Spiro, T. G.; Stigliani, W. M. Chemistry of the Environment; Prentice Hall: Upper Saddle River, NJ, 1996. (e) Cuenot, F.; Meyer, M.; Bucaille, A.; Guilard, R. A molecular approach to remove lead from drinking water. J. Mol. Liq. 2005, 118, 89-99. (f) Goyer, R. A. In Handbook on Toxicity of Inorganic Compounds; Seiler, H. G., Sigel, A., Sigel, H., Eds.; Marcel Dekker: NY, 1988. (g) Chisholm, J. J. Lead poisoning. Sci. Am. 1971, $224,15-23$.

(13) (a) Ghorai, P.; Dey, A.; Brandão, P.; Ortega-Castro, J.; Bauza, A.; Frontera, A.; Ray, P. P.; Saha, A. The development of a promising photosensitive Schottky barrier diode using a novel $\mathrm{Cd}(\mathrm{II})$ based coordination polymer. Dalton Trans. 2017, 46, 13531-13543. (b) Halder, S.; Dey, A.; Bhattacharjee, A.; Ortega-Castro, J.; 
Frontera, A.; Ray, P. P.; Roy, P. A Cd(II)-based MOF as a photosensitive Schottky diode: experimental and theoretical studies. Dalton Trans. 2017, 46, 11239-11249.

(14) (a) Ahmed, F.; Halder, S.; Dutta, B.; Islam, S.; Sen, C.; Kundu, S.; Sinha, C.; Ray, P. P.; Mir, M. H. Synthesis and structural characterization of a $\mathrm{Cu}(\mathrm{II})$-based $1 \mathrm{D}$ coordination polymer and its application in Schottky devices. New J. Chem. 2017, 41, 1131711323. (b) Bhattacharya, B.; Layek, A.; Alam, M. M.; Maity, D. K.; Chakrabarti, S.; Ray, P. P.; Ghoshal, D. Cd(II) based metal-organic framework behaving as a Schottky barrier diode. Chem. Commun. 2014, 50, 7858-7861.

(15) Sarma, K. P.; Poddar, R. K. A Convenient Method of Preparing Nickel(II) Thiocyanate and its Use in Synthesis. Transition Met. Chem. 1984, 9, 135-138.

(16) CrysAlis(Pro); Oxford Diffraction Ltd.: Oxford, U.K., 2005.

(17) (a) Sheldrick, G. M. A short history of SHELX. Acta Crystallogr., Sect. A: Found. Crystallogr. 2008, A64, 112-122. (b) Sheldrick, G. M. SHELXT-Integrated space-group and crystalstructure determination. Acta Crystallogr., Sect. A: Found. Adv. 2015, $71,3-8$.

(18) Spek, A. L. Acta Crystallogr. A 1990, 46, No. C34.

(19) Diamond, K. Molecular Structure Visualization, Crystal Impact GbR: Germany, Bonn, 2007.

(20) Burnett, M. N.; Johnson, C. K. ORTEP-3: Oak Ridge Thermal Ellipsoid Plot Program for Crystal Structure Illustrations; Report ORNL6895; Oak Ridge National Laboratory: Oak Ridge, TN, 1996.

(21) Macrae, C. F.; Bruno, I. J.; Chisholm, J. A.; Edgington, P. R.; McCabe, P.; Pidcock, E.; Monge, L. R.; Taylor, R.; van de Streek, J.; Wood, P. A. Mercury CSD 2.0 - new features for the visualization and investigation of crystal structures. J. Appl. Crystallogr. 2008, 41, 466470.

(22) Bhattacharyya, A.; Roy, S.; Chakraborty, J.; Chattopadhyay, S. Two new hetero-dinuclear nickel (II)/zinc (II) complexes with compartmental Schiff bases: Synthesis, characterization and self assembly. Polyhedron 2016, 112, 109-117.

(23) (a) Roy, S.; Dey, A.; Ray, P. P.; Ortega-Castro, J.; Frontera, A.; Chattopadhyay, S. Application of a novel 2D cadmium(II)-MOF in the formation of a photo-switch with a substantial on-off ratio. Chem. Commun. 2015, 51, 12974-12976. (b) Dutta, B.; Dey, A.; Naskar, K.; Ahmed, F.; Purkait, R.; Islam, S.; Ghosh, S.; Sinha, C.; Ray, P. P.; Mir, M. H. Cu(II)-Based binuclear compound for the application of photosensitive electronic devices. New J. Chem. 2018, 42, 8629-8637. (c) Dutta, B.; Dey, A.; Naskar, K.; Maity, S.; Ahmed, F.; Islam, S.; Sinha, C.; Ghosh, P.; Ray, P. P.; Mir, M. H. Two isostructural linear coordination polymers: the size of the metal ion impacts the electrical conductivity. New J. Chem. 2018, 42, 10309-10316. (d) Dutta, B.; Jana, R.; Sinha, C.; Ray, P. P.; Mir, M. H. Synthesis of a Cd(II) based 1D coordination polymer by in situligand generation and fabrication of a photosensitive electronic device. Inorg. Chem. Front. 2018, 5, 1998-2005. (e) Khan, S.; Halder, S.; Ray, P. P.; Herrero, S.; Gonzalez-Prieto, R.; Drew, M. G. B.; Chattopadhyay, S. A Semiconducting Copper(II) Coordination Polymer with $(4,4)$ Square Grid Topology: Synthesis, Characterization, and Application in the Formation of a Photoswitch. Cryst. Growth Des. 2018, 18, 651-659. (f) Roy, S.; Halder, S.; Drew, M. G. B.; Ray, P. P.; Chattopadhyay, S. Unprecedented photosensitivity of heterotrimetallic copper(II)/ sodium/mercury(II) coordination polymer based thin film semiconductor device. New J. Chem. 2018, 42, 6062-6076.

(24) Cheung, S. K.; Cheung, N. W. Extraction of Schottky diode parameters from forward current-voltage characteristics. Appl. Phys. Lett. 1986, 49, 85-87.

(25) Gupta, R. K.; Yakuphanoglu, F. Photoconductive Schottky diode based on $\mathrm{Al} / \mathrm{p}-\mathrm{Si} / \mathrm{SnS} 2 / \mathrm{Ag}$ for optical sensor applications. Solar Energy 2012, 86, 1539-1545.

(26) Jomaa, T. B.; Beji, L.; Ltaeif, A.; Bouazizi, A. The currentvoltage characteristics of heterostructures formed by MEH-PPV spincoated on n-type GaAs and n-type porous GaAs. Mater. Sci. Eng., C 2006, 26, 530-533.
(27) Das, M.; Datta, J.; Jana, R.; Sil, S.; Halder, S.; Ray, P. P. Synthesis of $\mathrm{rGO}-\mathrm{Zn}_{0.8} \mathrm{Cd}_{0.2} \mathrm{~S}$ via in situ reduction of GO for the realization of a Schottky diode with low barrier height and highly enhanced photoresponsivity. New J. Chem. 2017, 41, 5476-5486.

(28) Carbone, A.; Kotowska, B. K.; Kotowski, D. Space-ChargeLimited Current fluctuations in organic semiconductors. Phys. Rev. Lett. 2005, 95, No. 236601.

(29) Blom, P. W. M.; de Jong, M. J. M.; van Munster, M. G. Electricfield and temperature dependence of the hole mobility in poly $(\mathrm{p}$ phenylene vinylene). Phys. Rev. B. 1997, 55, R656-R659.

(30) Midddya, S.; Layek, A.; Dey, A.; Datta, J.; Das, M.; Banerjee, C.; Ray, P. P. Role of zinc oxide nanomorphology on Schottky diode properties. Chem. Phys. Lett. 2014, 610-611, 39-44.

(31) Das, M.; Datta, J.; Dey, A.; Jana, R.; Layek, A.; Middya, S.; Ray, P. P. One step hydrothermal synthesis of a $\mathrm{rGO}-\mathrm{TiO}_{2}$ nanocomposite and its application on a Schottky diode: improvement in device performance and transport properties. RSC Adv. 2015, 5, $101582-101592$. 